\title{
Improving patient outcomes in pulmonary hypertension
}

\author{
Nazzareno Galiè ${ }^{1}$, Vallerie V. McLaughlin², Lewis J. Rubin ${ }^{3}$ and \\ Gérald Simonneau ${ }^{4}$
}

Affiliations: 'Dept of Experimental, Diagnostic and Specialty Medicine-DIMES, University of Bologna, Bologna, Italy. ${ }^{2}$ Dept of Internal Medicine, Division of Cardiovascular Medicine, University of Michigan, Ann Arbor, MI, USA. ${ }^{3}$ Division of Pulmonary and Critical Care Medicine, University of California, San Diego, CA, USA. ${ }^{4}$ Hôpital Universitaire de Bicêtre, Université Paris-Sud, Le Kremlin Bicêtre, France.

Correspondence: Nazzareno Galiè, Dept of Experimental, Diagnostic and Specialty Medicine-DIMES, University of Bologna, Bologna, Italy. E-mail: nazzareno.galiedunibo.it

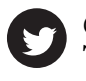

@ERSpublications

The updated management of PAH patients is leading to improvements in quality of life and outcome http://ow.ly/TAvMf

In recent years we have come a long way in our understanding of pulmonary hypertension (PH). As a result of ever-increasing experience in treating pulmonary arterial hypertension (PAH), and the availability of new treatment options, there have been continual improvements in patient outcomes. As patients are today living longer with this disease, there is now a focus on assessing the impact that PAH has on quality of life, and increased recognition that PAH management must aim to reduce this impact. The articles in this issue of European Respiratory Review discuss practical aspects of managing patients with $\mathrm{PH}$, look at the disease from the patient perspective, and review some of the latest strategies for diagnosis and treatment of this group of conditions. The authors, each of them experts in the field of $\mathrm{PH}$, delivered presentations at the 14th International Pulmonary Hypertension Forum held in March 2015 in Copenhagen, Denmark, upon which this series of reviews is based.

Patients with PAH face numerous challenges that impact their day-to-day living as a result of the debilitating and progressive nature of the condition. While the ultimate goal of PAH treatment is to improve survival, it should also be to improve patients' quality of life. We should remember that many $\mathrm{PAH}$ patients often do not look sick to others and it is thus important to question how often the impact of PAH on health-related quality of life (HRQoL) is considered. Delcroix and Howard [1] describe the burden of PAH on patients' physical, psychological and social well-being, and discuss the potential benefits of new tools in development for measuring the effect of PAH on HRQoL.

One way to reduce the burden of PAH is to diagnose patients early. To help achieve this goal, noninvasive imaging techniques have been developed to assist with screening, risk stratification and monitoring treatment outcomes in patients with PH. The review by GRÜNIG and PeAcock [2] focuses on how imaging techniques, including echocardiography and cardiac magnetic resonance, can provide complementary information about the volumetric and muscle mass limits of the heart. This review also highlights how improvements in imaging software and novel methodologies have the potential to influence how $\mathrm{PH}$ is diagnosed.

Although the diagnostic work-up of suspected $\mathrm{PH} / \mathrm{PAH}$ relies on noninvasive imaging techniques, confirmatory testing with right heart catheterisation (RHC) is essential [3]. RHC is an established and

Received: Aug 242015 | Accepted: Sept 012015

Conflict of interest: Disclosures can be found alongside the online version of this article at err.ersjournals.com

Provenance: Publication of this peer-reviewed article was sponsored by Actelion Pharmaceuticals Ltd, Allschwil, Switzerland (principal sponsor, European Respiratory Review issue 138).

Copyright OERS 2015. ERR articles are open access and distributed under the terms of the Creative Commons Attribution Non-Commercial Licence 4.0. 
recommended procedure; however, there is considerable variation in the methodology used that raises questions regarding consistency and accuracy. What are the potential pitfalls when carrying out this technique? And how is best practice ensured? Rosenkranz and Preston [4] address these points in their review, and provide specific guidance regarding RHC.

Despite the availability of reliable diagnostic techniques, differentiating non-PAH from other forms of $\mathrm{PH}$ can still be problematic. In $\mathrm{PH}$ associated with left heart disease, variation in presentation, disparities in the terminology used by the $\mathrm{PH}$ community and limitations in the design of clinical trials highlight that multiple unmet needs exist for this condition and there is still much to learn regarding the management of these patients. The review by FARBER and GIBBS [5] provides an overview of many of the challenges and complexities surrounding $\mathrm{PH}$ associated with left heart disease.

Real-life case studies, to further illustrate evidence gaps for identifying and managing complex forms of $\mathrm{PH}$, are presented in the case-based review by Olsson and PALAzZinI [6]. The authors refer to diverse cases, each reminding us of the importance of a multidisciplinary approach to patient management and that all presentations of $\mathrm{PH}$ warrant careful consideration.

An important challenge to overcome for all types of $\mathrm{PH}$ is how best to treat patients. Considerable progress has been made in the development of potential new therapies and evolving treatment strategies. Of these approaches, there is particular interest in drug combinations that simultaneously target the three major signalling pathways that are implicated in the pathology of the condition [2]. The article by LANG and GAINE [7] discusses current and future approaches in the treatment of PAH, focusing on the prostacyclin pathway, which is central to the pathophysiology of PAH. Targeting this pathway with drugs that offer convenience for the patient as well as sustained long-term benefits and improved safety and tolerability profiles is an unmet need that can be addressed by the availability of new agents, improved formulations, and advanced drug delivery devices.

Ever increasing experience in treating PAH, coupled with the availability of evolving treatment options [8], has led to improvements in patient outcomes. The series of reviews in this issue of European Respiratory Review together highlight the impact that PH has on patients' lives. Furthermore, they provide insight into current and future management strategies that aim to improve clinical outcomes and quality of life so that patients may live longer and healthier lives.

\section{Acknowledgements}

The 14th International Pulmonary Hypertension Forum on which the content of this review series is based was sponsored by Actelion Pharmaceuticals Ltd (Allschwil, Switzerland). The authors would like to thank Kate Bradford from PAREXEL (Worthing, UK) for medical writing assistance, funded by Actelion Pharmaceuticals Ltd.

\section{References}

1 Delcroix M, Howard L. Pulmonary arterial hypertension: the burden of disease and impact on quality of life. Eur Respir Rev 2015; 24: 621-629.

2 Grünig E, Peacock AJ. Imaging the heart in pulmonary hypertension: an update. Eur Respir Rev 2015; 24: 653-664.

3 Hoeper MM, Bogaard HJ, Condliffe R, et al. Definitions and diagnosis of pulmonary hypertension. J Am Coll Cardiol 2013; 62: Suppl., D42-D50.

4 Rosenkranz S, Preston IR. Right heart catheterization: best practice and pitfalls in pulmonary hypertension. Eur Respir Rev 2015; 24: 642-652.

5 Farber HW, Gibbs S. Under pressure: pulmonary hypertension associated with left heart disease. Eur Respir Rev 2015; 24: 665-673.

6 Olsson KM, Palazzini M. Challenges in pulmonary hypertension - managing the unexpected. Eur Respir Rev 2015; 24: 674-681.

7 Lang IM, Gaine SP. Recent advances in targeting the prostacyclin pathway in pulmonary arterial hypertension. Eur Respir Rev 2015; 24: 630-641.

8 Galiè N, Corris PA, Frost A, et al. Updated treatment algorithm of pulmonary arterial hypertension. J Am Coll Cardiol 2013; 62: Suppl., D60-D72. 